\title{
Dynamic Response Simulation of the Slope Triggered by Fluctuating Pressure during High Dam Flood Discharge
}

\author{
Hao-Hao Zhang, ${ }^{1,2}$ Jun-Xing Wang $\mathbb{D}^{1,2}$ Shuai-Qun Du, ${ }^{3}$ Li Chen $\mathbb{D}^{1,2}$ and Jin-Rong Da ${ }^{1,2}$ \\ ${ }^{1}$ State Key Laboratory of Water Resources and Hydropower Engineering Science, Wuhan University, Wuhan, China \\ ${ }^{2}$ Key Laboratory of Rock Mechanics in Hydraulic Structural Engineering of Ministry of Education, Wuhan University, \\ Wuhan, China \\ ${ }^{3}$ Power China, Guiyang Engineering Corporation Limited, Guiyang, China \\ Correspondence should be addressed to Jun-Xing Wang; jxwang@whu.edu.cn and Li Chen; 736023375@qq.com
}

Received 15 November 2021; Revised 10 December 2021; Accepted 13 December 2021; Published 18 January 2022

Academic Editor: Zhanbo Cheng

Copyright (c) 2022 Hao-Hao Zhang et al. This is an open access article distributed under the Creative Commons Attribution License, which permits unrestricted use, distribution, and reproduction in any medium, provided the original work is properly cited.

\begin{abstract}
The problem of slope vibration induced by flood discharge of high dams cannot be ignored. In this paper, this problem is simplified to be the relationship among the fluctuating pressures, the inherent properties of the slope system, and its dynamic responses. The characteristics of fluctuating pressures in the plunge pool during flood discharge are analyzed by the hydraulic model test. And a numerical slope model consisting of the finite element domain and the PML domain is established to study the inherent characteristics and vibration responses by numerical simulation. The results show that the flow fluctuation in plunge pool is a continuous and stable random vibration process. And the fluctuating pressures on the bottom area of the plunge pool are greater than that of the sidewall, but the fluctuation phenomenon at the sidewall is more intense. In addition, the slope displacement vibration intensity caused by fluctuating pressures is small, only at the micron level. The fluctuating pressures on the bottom area of the plunge pool are the dominant factor affecting the kinetic energy density distribution of the slope. This work provides a simple and efficient method for the study of slope vibration induced by high dam flood discharge.
\end{abstract}

\section{Introduction}

The failure behavior of natural slopes has always been a research hotspot in geotechnical, mining, and hydropower engineering $[1-3]$, and the content mainly involves indoor rock tests [4-7], large-scale slope failure analysis [8,9], and many other aspects. There are a large number of weak joint planes within the natural slope, which makes the slope show different failure characteristics under the influence of external forces such as excavation $[10,11]$, earthquake [12], and blasting [13]. And many scholars have done a lot of research in many aspects. However, there are few studies on the vibration response of slope caused by water flow impact during high dam flood discharge. In 1979, the Zhigulevskaya Hydroelectric Power Station induced vibrations in a certain area around the site during flood discharge, which caused cracks in the houses in residential areas and threatened the psychology and safety of residents $[14,15]$. In the 1980s, Harza Corporation of the United States proposed that special attention should be paid to the arch dam and vibration at the foundation site induced by flood discharge at the Ertan Hydroelectric Power Station [16]. In China, the Xiangiiaba, Xiluodu, and Jin'anqiao hydropower stations also caused vibration of adjacent slope and residential area in flood season, which had a serious impact on residents' lives [17-19]. The vibration issue induced by the impact of water flow during flood discharge of high dams cannot be ignored.

The methods to research the vibration response induced by high dam flood discharge mainly include prototype observation, physical model test, and numerical simulation. Prototype observation can only be used in the operation in situ, and physical model test and numerical simulation can be used in both design and operation. The physical model test simulates the actual terrain and operating conditions 
based on similarity criteria in the laboratory and is often used for water flow characteristics analysis and dam safety evaluation [20-22]. It can be classified into the ordinary hydraulic model and the hydroelastic model. The ordinary hydraulic model follows the similarity criteria of hydraulics and is generally used to study the characteristics of the water flow pattern, velocity, and fluctuating pressure. The hydroelastic model satisfies the similarity criteria of hydraulics and structural dynamics at the same time and is used to study not only the characteristics of the water flow pattern, velocity, and fluctuating pressure, but also the responses of the model structure under hydrodynamic pressure [23]. However, as the slope is a complex discontinuous geological mass, the hydroelastic model cannot truly restore the strata structure characteristics. Under the excitation of fluctuating pressures, the stress waves generated within the model produce reflections, scattering, and other phenomena at the boundary, which easily distort the results of the vibration response test. Compared with the prototype observation and physical model test, numerical simulation is characterized by the advantages of convenience, timesaving, and labor-saving in studying the vibration response of slope structures.

The numerical simulation of flood discharge vibration is based on the fluctuating pressure data of the hydraulic model test $[24,25]$, and the selection of dynamic boundary conditions is one of the key issues in the simulation. The commonly used dynamic boundary conditions mainly include viscous boundary conditions, absorption boundary conditions, and the infinite element method [26, 27]. The viscous boundary has been widely used in major commercial simulation software (like FLAC 3D, 3DEC, COMSOL Multiphysics, etc.) due to its simple principle and easy implementation [28-31]. But it has a poor absorption effect for large-angle incident waves or surface waves and cannot effectively simulate the propagation characteristics of stress waves generated by fluctuating pressures in slope. The latter two methods can be used to simulate the propagation characteristics of stress waves generated by fluctuating pressures in slope strata. In terms of simulation accuracy, absorbing boundary conditions have great advantages and are often used in frequency domain calculations to simulate the propagation of acoustic and electromagnetic waves. The perfectly matched layer (PML) is a kind of layered absorbing boundary, which can be used for both frequency domain and time domain calculation of elastic waves. The high-precision layered absorbing boundary is the most widely used in current time domain elastic near-field wave numerical simulation [32-34]. It can be obtained by the complex coordinate extension of the infinite wave equation [35]. The vibration of the acoustic wave, electromagnetic wave, and elastic wave can be simulated by combining with the finite element method and finite difference method [36]. Its appearance provides strong technical support for related research on slope vibration induced by fluctuating pressures during high dam flood discharge. So, analyzing the fluctuating pressure characteristics by ordinary hydraulic model test and using the numerical simulation combining PML technology and finite element method to study the vibration response characteristics may be a better and more effective method to study the vibration response triggered by high dam flood discharge.

Fluctuating pressure generated by the impact of water flow is transformed into the stress wave by the turbulent water body acting on the concrete structure, and then the stress wave propagates along the slope surface or inside the rock layer in the form of body wave and surface wave. It is characterized by low frequency, long-holding time, and cyclic repetition. Based on the "excitation-response" mechanism [37], the vibration response of fluctuating pressures on the slope during high dam flood discharge can be simplified into a study of the characteristics of fluctuating pressures, the inherent characteristics of slope strata structure, and the slope dynamic response and the relationship among them (Figure 1). The slope strata structure can be regarded as a system, and the fluctuating pressure can act as the excitation input onto the slope system. By analyzing the inherent properties of the slope system, the characteristic frequency and damping ratio of the slope were calculated. On this basis, the vibration responses of the slope system under the excitation of fluctuating pressures were studied, including the slope displacement, velocity, and stress. The research steps on the slope dynamic response under fluctuating pressures can be described as follows: (1) The hydraulic physical model test is used to obtain time history curves of fluctuating pressures during the high dam flood discharge, and the magnitude and distribution characteristics of fluctuating pressures were analyzed by wavelet analysis. (2) According to the actual slope stratum structure, a slope numerical model with PML domain is established, and the characteristic frequency and damping coefficient are calculated through the prestress modal analysis method. (3) Time history curves of fluctuating pressures obtained from the model test were applied to the numerical model for slope dynamic response simulation, and the characteristics of displacement, vibration intensity, and kinetic energy distribution of the slope system under fluctuating pressures are analyzed.

In this paper, the spillway discharge process of a hydropower station is taken as an example. The hydraulic model test is carried out for the spillway discharge process of the hydropower station in Section 2, the time history curve of the fluctuating pressures is obtained, and the characteristics of fluctuating pressures in the plunge pool are analyzed. Then in Section 3, the fluctuating pressure data are applied to the numerical slope model with PML domain, and the characteristics of slope vibration under fluctuating pressures are analyzed. And the paper ends with a brief conclusion in Section 4. This work provides a simple and efficient method for the study of slope vibration induced by high dam flood discharge and further indicates the feasibility of hydraulic model test and numerical simulation combined method to study this issue.

\section{Hydraulic Model Test of Fluctuating Pressures}

2.1. Research Background. The altitude of the hydropower station is $3000 \mathrm{~m}$ with a dam height of $315 \mathrm{~m}$. Energy is 


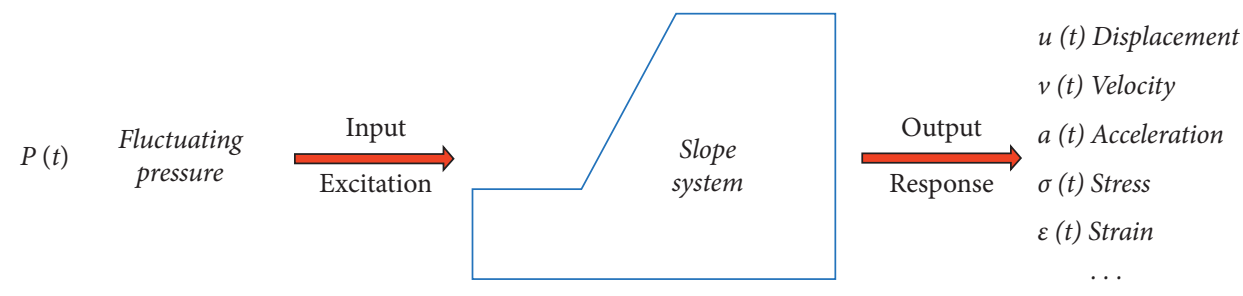

FIgURE 1: Relationship between excitation and response of the slope dynamic system.

dissipated by three spillways, a flood discharging tunnel, and a plunge pool. During flood discharge, the maximum flow rate is $13000 \mathrm{~m}^{3} / \mathrm{s}$ and the maximum flow velocity is $50 \mathrm{~m} / \mathrm{s}$. High-speed water flows through the spillway into the plunge pool and has strong turbulent shear and diffusion with the surrounding water, accompanied by a severe fluctuation phenomenon. The plunge pool is the main area where energy is dissipated and turbulent vortices are generated or disappeared. The fluctuating pressure acts on the bottom plate and sidewall of the plunge pool, causing the structure of the plunge pool to vibrate. As it spreads to the distance in the form of stress waves, vibrations in the surrounding slopes and buildings will be caused. In this process, the vibration of the plunge pool structure induced by fluctuating pressures can be considered as the source of vibration. The analysis of the slope dynamic response triggered by fluctuating pressures is particularly important. The method of the hydraulic model test was adopted to conduct the research.

2.2. Experimental Scheme. To analyze the fluctuating pressure characteristics on the bottom plate and sidewall of plunge pool during flood discharge and to provide relevant parameters for the slope dynamic response simulation under the fluctuating pressures, we designed the hydraulic physical model according to the similarity criteria, and the model layout was shown in Figure 2. The model mainly included five parts: gate, tunnel section, open-cut section, flip bucket, and plunge pool. Comprehensively considering the impact of the test site, water supply capacity, model materials, and spillway model layout, the model scale of the plunge pool was determined as $\lambda_{\mathrm{L}}=80$. According to the gravity similarity criterion, the fluctuating pressure scale was $\lambda_{\mathrm{P}}=\lambda_{\mathrm{L}}=80$, and the time scale was $\lambda_{\mathrm{P}}=\lambda_{\mathrm{L}}{ }^{1 / 2}=\sqrt{80}$. The test results were restored to the prototype scale for analysis based on similarity criteria.

Fluctuating pressure measuring points were mainly arranged in the discharge impact area of the plunge pool and were arranged symmetrically with the discharge axis as the central axis. A total of 45 measuring points were set, including 10 points (No.36 45) in the sidewall and 35 points (No.1 35) in the bottom plate, and the measuring points diagram is shown in Figure 2(b). The model test flow was controlled by an electromagnetic flowmeter located at the inlet of the spillway. And fluctuating pressures at measuring points were collected by the fluctuating pressure test instrument in the Hydraulic Laboratory of Wuhan University (Figure 3(a)). The sampling frequency is $100 \mathrm{~Hz}$, and the sampling time is $100 \mathrm{~s}$.
The model test condition was the discharge situation with the gate of the third spillway fully opened, and the fluctuating pressure data at the measuring points on the bottom plate and sidewall of the plunge pool were collected by the fluctuating pressure tester for analysis. The test steps can be described as follows:

(i) Install the fluctuating pressure test instrument and fill the reservoir to make the water level rise to the predetermined upstream water level.

(ii) Open the gate to discharge the water; when the depth of the plunge pool is close to the predetermined level, control the discharge flow to make the flow in a stable discharge state.

(iii) After the water flow stabilized for 15 minutes, the collection of data from fluctuating pressure was carried out. A total of 10 data groups were collected, with an interval of 15 minutes for each of the two groups (Figure 3(b)).

2.3. Analysis of Tested Results. The discharge water flows through the tunnel section and open-cut section of the spillway to reach the flip bucket and makes a horizontal throwing motion at the end of the flip bucket to enter the plunge pool. The exit velocity at the end of the flip bucket is $47.91 \mathrm{~m} / \mathrm{s}$, and the water flow enters the water at a depression angle. The entry angle is about $30^{\circ}$, and the water tongue falls on the water surface at the No.17 measurement point. After the flow enters the plunge pool, a large surface vortex roll area is formed in front of the water drop point, which impacts the sidewall. The phenomenon of aeration in the water body of the vortex roll area is obvious, and the energy exchange is sufficient, making the water show white foam. The upstream side of the discharge axis has a large space, the water surface is relatively gentle, and the water body contains less air, which is not involved in energy dissipation. The peak and mean values of fluctuating pressure at measuring points are shown in Table 1 . The maximum and minimum fluctuating pressures at the drop point of the bottom of the water tongue drop point (No.17 measuring point) are $1091.88 \mathrm{kPa}$ and $885.16 \mathrm{kPa}$, respectively, with an average value of $1007.01 \mathrm{kPa}$. The maximum and minimum time-average pressure at the sidewall where the water flow impacts (No.40 measuring point) are $1031.10 \mathrm{kPa}$ and $705.95 \mathrm{kPa}$, with an average value of $865.76 \mathrm{kPa}$. The maximum time-average fluctuating pressure on the bottom plate of the plunge pool is $1190.93 \mathrm{kPa}$ at the No.31 measuring point, and the 


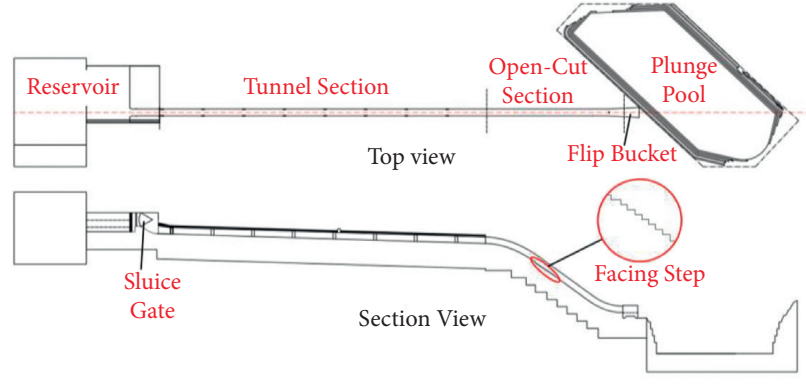

(a)

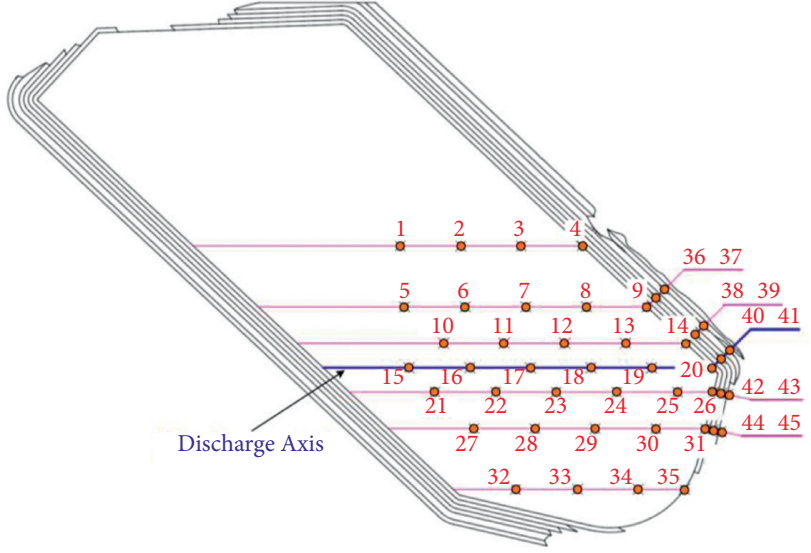

(b)

FIGURE 2: Layout plan of the hydraulic model test and measuring points of fluctuating pressures. (a) Layout of the hydraulic model test. (b) Measuring points diagram of fluctuating pressures.

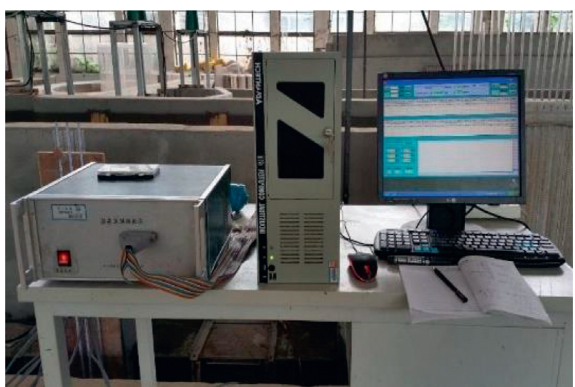

(a)

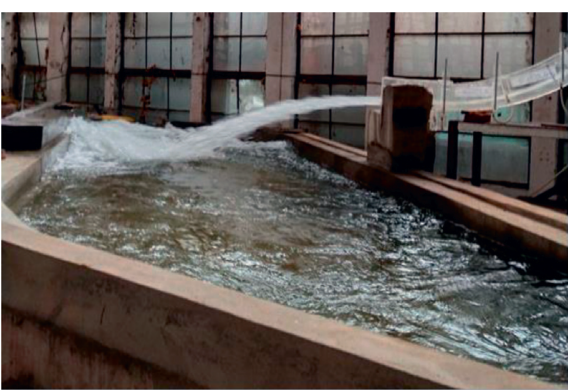

(b)

FIGURE 3: Photos of testing instruments and experimental process. (a) Fluctuating pressure testing instrument. (b) Experimental process.

TABle 1: Peak values and mean values of measuring points.

\begin{tabular}{|c|c|c|c|c|c|c|c|}
\hline Measuring points & Maximum $(\mathrm{kPa})$ & Minimum $(\mathrm{kPa})$ & Mean $(\mathrm{kPa})$ & Measuring points & Maximum $(\mathrm{kPa})$ & Minimum $(\mathrm{kPa})$ & Mean $(\mathrm{kPa})$ \\
\hline 2 & 1020.65 & 810.34 & 963.56 & 29 & 953.52 & 743.32 & 873.19 \\
\hline 3 & 1092.96 & 922.69 & 1011.21 & 30 & 1086.72 & 868.52 & 1001.11 \\
\hline 4 & 1090.79 & 919.20 & 1014.40 & 31 & 1190.93 & 932.53 & 1074.01 \\
\hline 6 & 1082.21 & 897.75 & 1005.30 & 32 & 1096.18 & 902.38 & 1014.11 \\
\hline 7 & 1093.61 & 883.31 & 990.80 & 33 & 1071.68 & 880.12 & 998.11 \\
\hline 8 & 1100.49 & 898.08 & 1011.92 & 34 & 1072.15 & 866.14 & 986.38 \\
\hline 10 & 967.23 & 783.18 & 897.77 & 35 & 1122.44 & 925.32 & 1044.05 \\
\hline 11 & 1052.49 & 872.80 & 984.43 & 36 & 1043.60 & 794.79 & 917.78 \\
\hline 13 & 1046.14 & 867.35 & 967.76 & 37 & 968.18 & 792.49 & 900.48 \\
\hline 14 & 1113.87 & 921.04 & 1036.56 & 38 & 1203.64 & 858.84 & 1011.56 \\
\hline 15 & 1109.58 & 942.46 & 1047.29 & 39 & 1249.51 & 764.77 & 1015.73 \\
\hline 16 & 1047.89 & 867.72 & 975.67 & 40 & 1031.10 & 705.95 & 865.76 \\
\hline 17 & 1091.88 & 885.16 & 1007.01 & 41 & 1166.58 & 780.30 & 963.97 \\
\hline 18 & 950.11 & 783.18 & 891.24 & 42 & 1104.19 & 864.50 & 981.84 \\
\hline 19 & 999.19 & 810.34 & 916.57 & 43 & 916.75 & 706.78 & 807.96 \\
\hline 22 & 941.55 & 770.34 & 871.86 & 44 & 1193.21 & 880.76 & 1047.80 \\
\hline 25 & 1058.91 & 829.04 & 964.01 & 45 & 1156.48 & 889.46 & 1041.36 \\
\hline 26 & 1086.72 & 928.42 & 1007.84 & & & & \\
\hline
\end{tabular}

Note. Abnormal data of the measuring point is not listed. 
maximum time-average pressure at the sidewall is $1249.51 \mathrm{kPa}$ at the No.39 measuring point.

To obtain the vibration distribution characteristics of fluctuating pressures in the plunge pool, the standard deviation was obtained through statistical analysis of the fluctuating pressure data. The standard deviation distribution diagram of the fluctuating pressures was drawn in Figure 4. Overall, the standard deviations of the fluctuating pressures at the measuring points on the sidewall and close to the sidewall are larger than those at the measuring points in the middle of the bottom plate, indicating that the fluctuation phenomenon on the sidewall is stronger than the area of the bottom plate. As far as the bottom plate of the middle of the plunge pool bottom plate is concerned, the standard deviation at the No.17 measuring point is greater than that of its adjacent measuring points, indicating that the incident water flow has a greater impact on the water body of the plunge pool. This caused severe turbulence near the drop point of the water tongue. The standard deviations of the fluctuating pressures at the measuring points of the sidewall are large, which indicates that the water turbulence near the sidewall is strong. The water flow turbulence near the sidewall is not caused by the direct impact of the water flow, but by the turbulent energy associated with the severe vortex after the incident water flows diving into the surface water body.

The Daubechies wavelet was used to decompose the fluctuating pressure signals at the measurement points No.17 and No.40 obtained by the model test in four-layer wavelet decomposition. The sampling frequency in the test is $100 \mathrm{~Hz}$ and the Nyquist cut-off frequency is $50 \mathrm{~Hz}$ according to the sampling theorem. Combined with the frequency scale of the model test, the analysis frequency of the fluctuating pressure in the prototype is $5.5902 \mathrm{~Hz}$. The wavelet decomposition follows:

$$
s=a 4+d 1+d 2+d 3+d 4,
$$

where $s$ is the original signal, and $\mathrm{d} 1, \mathrm{~d} 2, \mathrm{~d} 3, \mathrm{~d} 4$, and a 4 are the signals of each frequency band after decomposition, respectively.

The wavelet decomposition diagrams of measurement points 17 and 40 were shown in Figure 5. In Figure 5, the wavelet decomposition of the original fluctuating pressure signal can be decomposed into five frequency bands: $0-0.3494 \mathrm{~Hz}(\mathrm{a} 4), \quad 0.3494-0.6988 \mathrm{~Hz}(\mathrm{~d} 4), \quad 0.6988-1.3975 \mathrm{~Hz}$ (d3), $1.3975-2.7951 \mathrm{~Hz}(\mathrm{~d} 2)$, and $2.7951-5.5902 \mathrm{~Hz}$ (d1). The variance of the signal in each frequency band after wavelet decomposition was counted, and the frequency range and variance of the signal in each frequency band and the variance occupation are shown in Table 2.

In Table 2, the difference between the total variance of the fluctuating pressures in all frequency bands after wavelet decomposition and the original signal variance is very small. Considering the calculation error, they were considered equal:

$$
\sigma^{2}=\sigma_{a 4}^{2}+\sigma_{d 4}^{2}+\sigma_{d 3}^{2}+\sigma_{d 2}^{2}+\sigma_{d 1}^{2} .
$$

$\sigma^{2}$ is the total variance, and $\sigma_{i}^{2}$ is the variance of different frequency bands, $\mathrm{kPa}^{2}, i=d 1, \mathrm{~d} 2, \mathrm{~d} 3, \mathrm{~d} 4, \mathrm{a} 4$.

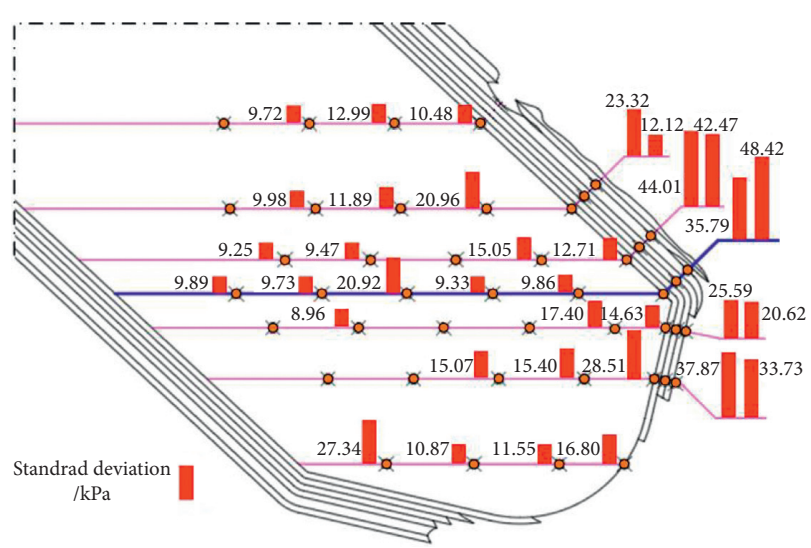

Figure 4: Standard deviation distribution of fluctuating pressures.

Since the variance of the fluctuating pressures characterizes the average power of the fluctuating pressure signal, it is known from (2) that the energy before and after wavelet decomposition is conserved. From [38, 39], the low frequency signal of the fluctuating pressure signal after wavelet decomposition corresponds to the fluctuation of the largescale vortices and the high frequency signal corresponds to the fluctuation of the small-scale vortices.

The variance of fluctuating pressure at the No.17 measuring point is $388.4841 \mathrm{kPa}^{2}$ in the frequency band of $2.7951-5.5902 \mathrm{~Hz}$, accounting for $88.81 \%$ of the total variance of all frequency bands. It indicates that the fluctuation of small-scale vortices dominates the water flow fluctuation at the No.17 measuring point, with a short fluctuation period and high frequency. The viscous shear effect of small-scale vortices in the water body is strong. But the variance of the fluctuating pressure at the No.40 measuring point of the sidewall in the frequency band of $0-0.3494 \mathrm{~Hz}$ is $859.6624 \mathrm{kPa}^{2}$, accounting for $67.14 \%$ of the total variance of all frequency bands. The fluctuation phenomenon is mainly generated by the fluctuation of large-scale vortices, which corresponds to the turbulence phenomenon of the surface vortex roll area in front of the water tongue drop point in the plunge pool.

Based on the excitation-response characteristics of the slope under the fluctuating pressures in Figure 1, the original signals at the measuring points No.17 and No.40 in Figure 5 were used as the "excitation" to study the vibration response of the slope in the following numerical simulations.

\section{Numerical Simulation of the Slope Dynamic Response}

\subsection{Simulation Principle}

3.1.1. Prestressed Modal Analysis and Rayleigh Damping. The inherent characteristics of the slope vibration problem mainly refer to its characteristic frequency and damping characteristics. Here, the prestressed modal analysis method was used to obtain the characteristic frequency and damping ratio of the slope system. Prestressed modal analysis refers to the static analysis of the slope system under the action of the time-average fluctuating pressures to obtain the second 


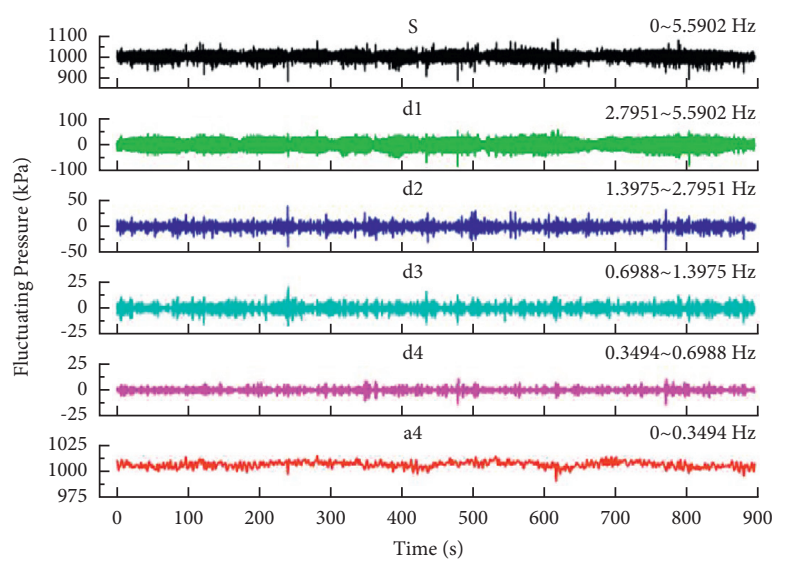

(a)

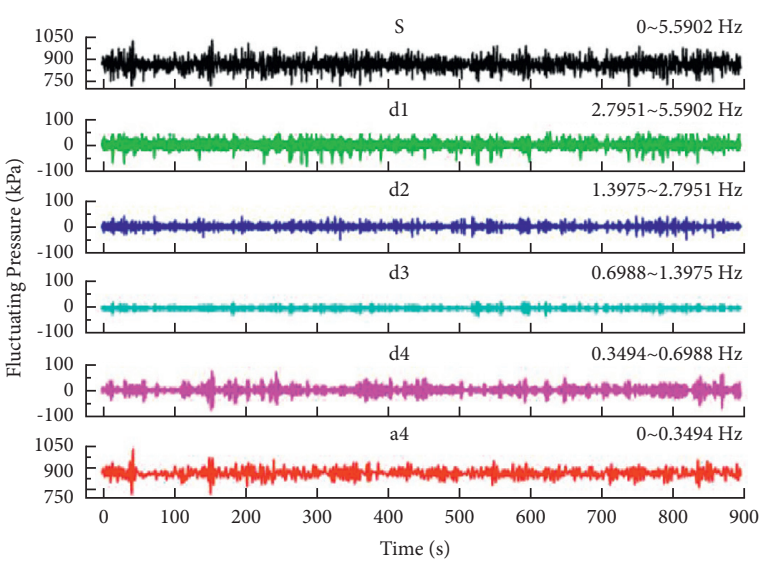

(b)

FIgURE 5: Fluctuating pressures time history curves at No.17 and No.40 measuring points. (a) No.17 measuring point. (b) No.40 measuring point.

TABle 2: Variance and proportion of fluctuating pressures in each frequency band.

\begin{tabular}{|c|c|c|c|c|c|}
\hline \multirow{2}{*}{ Frequency band } & \multirow{2}{*}{ Frequency range } & \multicolumn{2}{|c|}{ No.17 measuring point } & \multicolumn{2}{|c|}{ No.40 measuring point } \\
\hline & & Variance $\left(\mathrm{kPa}^{2}\right)$ & Proportion (\%) & Variance $\left(\mathrm{kPa}^{2}\right)$ & Proportion (\%) \\
\hline $\mathrm{a} 4$ & $0-0.3494$ & 8.7557 & 2.00 & 859.6624 & 67.14 \\
\hline $\mathrm{d} 4$ & $0.3494-0.6988$ & 5.0400 & 1.15 & 219.9289 & 17.18 \\
\hline $\mathrm{d} 3$ & $0.6988-1.3975$ & 10.7060 & 2.45 & 34.0706 & 2.66 \\
\hline $\mathrm{d} 2$ & $1.3975-2.7951$ & 24.4629 & 5.59 & 51.1225 & 3.99 \\
\hline $\mathrm{d} 1$ & $2.7951-5.5902$ & 388.4841 & 88.81 & 115.5625 & 9.03 \\
\hline \multicolumn{2}{|c|}{ Total variance } & 437.4487 & 100.00 & 1280.3469 & 100.00 \\
\hline \multicolumn{2}{|c|}{ Original signal variance $\sigma^{2}$} & 437.6464 & - & 1280.9241 & - \\
\hline
\end{tabular}

Piola-Kirchhoff stress, and then it is added to the stress tensor in the form of prestress for modal analysis. After obtaining the characteristic frequency and damping ratio of the slope system, it is necessary to analyze the damping form of the slope vibration problem.

Rayleigh damping is not directly related to the physical properties of materials, so it is often used in geotechnical engineering. The damping matrix is a linear combination of the mass matrix and the stiffness matrix. $\alpha$ and $\beta$ are the damping constants related to the mass matrix and the stiffness matrix, respectively. Rayleigh damping constants $\alpha$ and $\beta$ can be obtained by the following equation:

$$
\alpha+\beta \omega_{i}=2 \omega_{i} \xi_{i}
$$

$\omega_{i}$ is the angular frequency of the slope system and $\xi_{i}$ is the damping ratio corresponding to $\omega_{i}$.

Rayleigh damping directly acts on the virtual work equation and does not affect the constitutive relationship of the material. It can be applied to both time domain and frequency domain analysis. Rayleigh damping was used to study the vibration response characteristics of the slope.

3.1.2. Perfectly Matched Layer (PML). The dynamic boundary condition is a key issue in the simulation of slope dynamic response. The PML technology was used in this paper to reduce the influence of stress wave reflections on the simulation results. The PML is a layered absorbing boundary condition, which can be considered as an added domain along the outside of the simulation domain to absorb all outgoing waves. The PML can absorb all outgoing waves well and will not reflect at the interface between the PML domain and the simulation domain. Therefore, PML technology has a great attraction for dealing with the propagation of acoustic waves, elastic waves, and electromagnetic waves.

In Bérenger's PML equations, the unknowns are usually split into the sum of nonphysical components, so it is also called the split PML. And the other PML is based on the complex coordinate stretching transformation of the PML domain. Barbara Kaltenbacher derived the PML equations of the second-order wave equations in the time domain based on the PML equations in the frequency domain. According to [32], the control equations of the PML in the frequency domain and time domain can be described by the following equations.

The frequency domain equation is as follows:

$$
\begin{aligned}
& \frac{(j \omega)^{2}}{c^{2}} p-\frac{1}{f^{\prime}\left(x_{i}\right)} \frac{\partial}{\partial x_{i}}\left(\frac{1}{f^{\prime}\left(x_{i}\right)} \frac{\partial}{\partial x_{i}}\right)=0, \\
& \left(\tilde{x}_{i} \in C, d \tilde{x}_{i}=f^{\prime}\left(x_{i}\right) d x_{i}=\frac{1+\sigma\left(x_{i}\right)}{j \omega}, \quad x_{i} \in\{x, y, z\}\right) .
\end{aligned}
$$


And, the time domain equation is

$$
\begin{aligned}
& \frac{1}{c^{2}}\left(\frac{\partial^{2} p}{\partial t^{2}}+\sigma_{i} \frac{\partial p}{\partial t}\right)-\frac{\partial}{\partial x_{i}}\left(u_{i}+\frac{\partial p}{\partial x_{i}}\right)=0, \frac{\partial u_{i}}{\partial t}+\sigma_{i}\left(u_{i}+\frac{\partial p}{\partial x_{i}}\right)=0, \\
& \left(\sigma_{i} \in\left\{\sigma_{x}, \sigma_{y}, \sigma_{z}\right\}, u_{i} \in\left\{u_{x}, u_{y}, u_{z}\right\}\right),
\end{aligned}
$$

where $c$ is the wave velocity; $\tilde{x}_{i}$ is the coordinate transformation function in the PML domain; $\sigma\left(x_{i}\right)=\sigma_{i}$ is the damping function in the PML domain; $u_{i}$ is the auxiliary variable.

3.2. Simulation Schemes. To analyze the vibration responses of fluctuating pressures generated during the discharge of the hydropower station on the surrounding slope, we took the discharge axis in Figure 2(b) as the section line to make the strata profile and established the slope numerical model as shown in Figure 6. Point $\mathrm{O}$ is the origin of the coordinates. The model strata are divided according to the actual strata lithology. The physical and mechanical parameters of different rock strata are shown in Table 3. Four monitoring points, numbered A-D, were placed on the left slope surface of the model to monitor the slope displacement. To analyze the change in slope kinetic energy under the action of fluctuating pressures, the EF line was made at the same elevation as the plunge pool floor, and a monitoring point was taken every $100 \mathrm{~m}$ on the EF line, with 11 monitoring points in total (including points $\mathrm{E}$ and $\mathrm{F}$ ). The variation of kinetic energy density with distance was fitted to analyze the attenuation characteristics of kinetic energy.

The numerical simulation is realized by COMSOL Multiphysics and MATLAB. The slope model was composed of the finite element domain and the PML domain. The inner model was the finite element domain, and the two sides and the bottom were the PML domains. The outer boundary of the PML domains was imposed with a normal constraint, and the upper surface of the model was a free boundary.

The blue line in Figure 6 was the position where fluctuating pressures were applied. The fluctuating pressures were the original time history data measured at No.17 and No.40 measuring points as shown in Figure 5. And the point-to-surface conversion coefficient of fluctuating pressures was 0.4 [25]. The first two eigenfrequencies of the model obtained by the prestress modal analyses were $0.3789 \mathrm{~Hz}$ and $0.3821 \mathrm{~Hz}$, and the corresponding damping ratios were 0.7996 and 0.5963 , respectively.

The simulations of slope dynamic response include two scenarios:

Scenario I: The time history data of fluctuating pressures at the No.17 measuring point were applied to the floor area of the model plunge pool, the calculation time was $100 \lambda_{t} s$, and the data was collected once at an interval of $0.01 \lambda_{\mathrm{t}} s$.

Scenario II: The time history data of fluctuating pressures at the No.17 measuring point and the No.40 measuring point were applied to the floor area and sidewall of the model plunge pool, the calculation time was $100 \lambda_{\mathrm{t}} s$, and the data was collected once at an interval of $0.01 \lambda_{t} s$.

\subsection{Results and Discussion}

3.3.1. Evolution of Dynamic Displacement. Displacement is an important index of slope dynamic response, which can

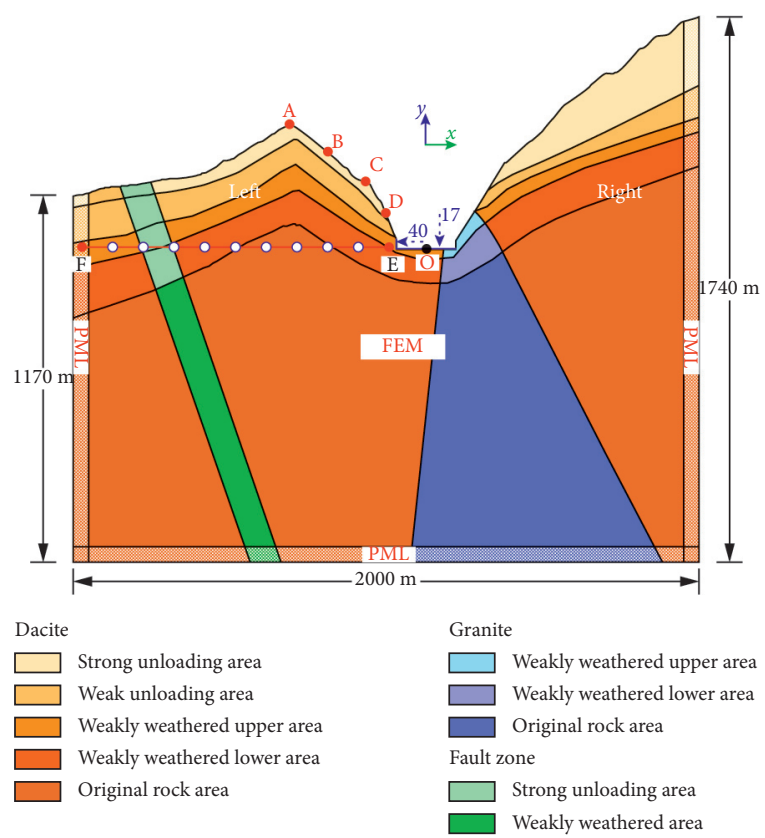

FIGURE 6: Numerical model of slope and layout of monitoring points.

directly reflect the slope deformation under fluctuating pressures. The time history curves of the slope displacement at the monitoring points A-D are shown in Figure 6. As the loading time increases, the dynamic displacement evolution of the slope can be divided into two stages.

Stage I: Initial severe vibration stage $(0 \sim 5 \mathrm{~s})$. At this stage, under fluctuating pressures, the original stress balance of the model slope is broken, resulting in severe vibration. From Figure 5 in Section 2.3, it can be identified that the flow fluctuation process is a stable random vibration process. The dynamic displacement response of the slope should also be shown as a relatively stable random vibration, and the initial severe vibration stage is not representative.

Stage II: Stable random vibration stage $(>5 \mathrm{~s})$. In this stage, the slope displacement gradually stabilizes after severe vibration and carries out random vibration within a certain range. The random vibration of the slope system caused by fluctuating pressures is obvious. Therefore, the following analysis is based on the slope response data at this stage.

In Figure 7(a), the X-displacement of each monitoring point is positive, which indicates that the left side slope deforms towards the freeing surface region under the action of fluctuating pressures. The higher the elevation, the greater the deformation amplitude. In Scenario I, the X-displacement of each monitoring point is larger than that in Scenario II. The fluctuating pressure on the sidewall of the plunge pool restrains the deformation from slope to free surface to a certain extent. In Figure 7(b), the Y-displacement of each monitoring point is negative, indicating that compression deformation occurs on the slope, and the higher the elevation is, the smaller the deformation amplitude is. The change of Y-displacement under the two conditions is almost the same, indicating that the influence of fluctuating pressures on the Y-displacement of the slope is small. 
TABLE 3: Simulation parameters.

\begin{tabular}{|c|c|c|c|c|c|c|}
\hline Lithology & & Density $\left(\mathrm{kg} / \mathrm{m}^{3}\right)$ & Poisson's ratio & $\begin{array}{c}\text { Elastic modulus } \\
(\mathrm{GPa})\end{array}$ & $\begin{array}{l}\text { Cohesion } \\
(\mathrm{MPa})\end{array}$ & $\begin{array}{l}\text { Friction } \\
\text { coefficient }\end{array}$ \\
\hline \multirow{5}{*}{ Dacite } & Strong unloading area & 2450 & 0.22 & 26.8 & 0.9 & 0.8 \\
\hline & Weak unloading area & 2500 & 0.23 & 29.5 & 1.2 & 1.1 \\
\hline & Weakly weathered upper area & 2550 & 0.22 & 31.8 & 0.8 & 0.85 \\
\hline & Weakly weathered lower area & 2660 & 0.22 & 34.2 & 0.9 & 0.9 \\
\hline & Original rock area & 2670 & 0.22 & 36.1 & 1.5 & 1.3 \\
\hline \multirow{3}{*}{ Granite } & Weakly weathered upper area & 2580 & 0.21 & 29 & 0.9 & 0.8 \\
\hline & Weakly weathered lower area & 2650 & 0.23 & 33.3 & 1.2 & 1.1 \\
\hline & Original rock area & 2690 & 0.2 & 40.1 & 1.6 & 1.3 \\
\hline \multirow{2}{*}{ Fault zone } & Strong unloading area & 2418 & 0.30 & 8 & 0.15 & 0.5 \\
\hline & Weakly weathered area & 2630 & 0.25 & 11.5 & 0.15 & 0.5 \\
\hline
\end{tabular}

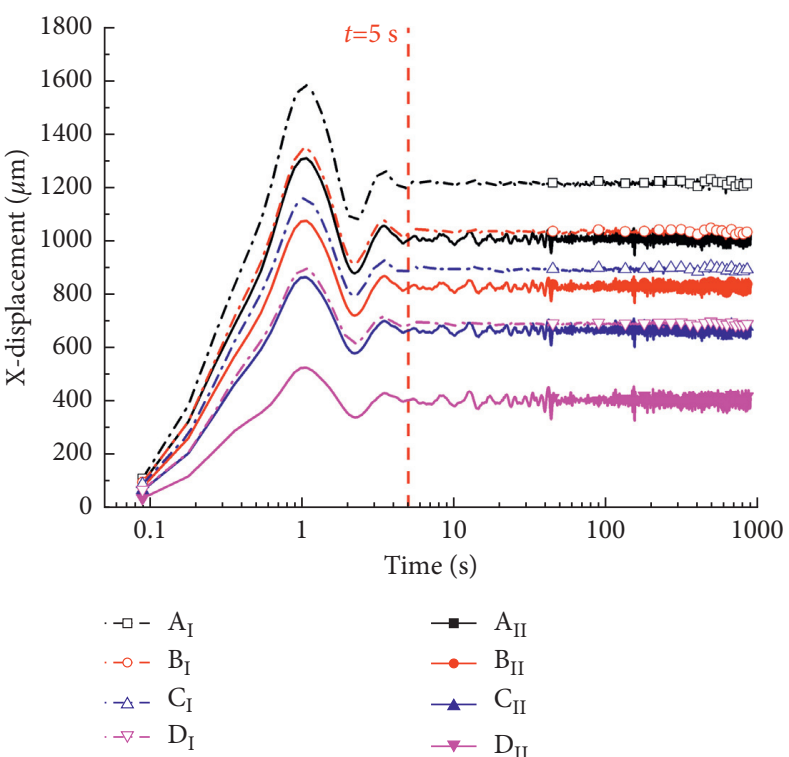

(a)

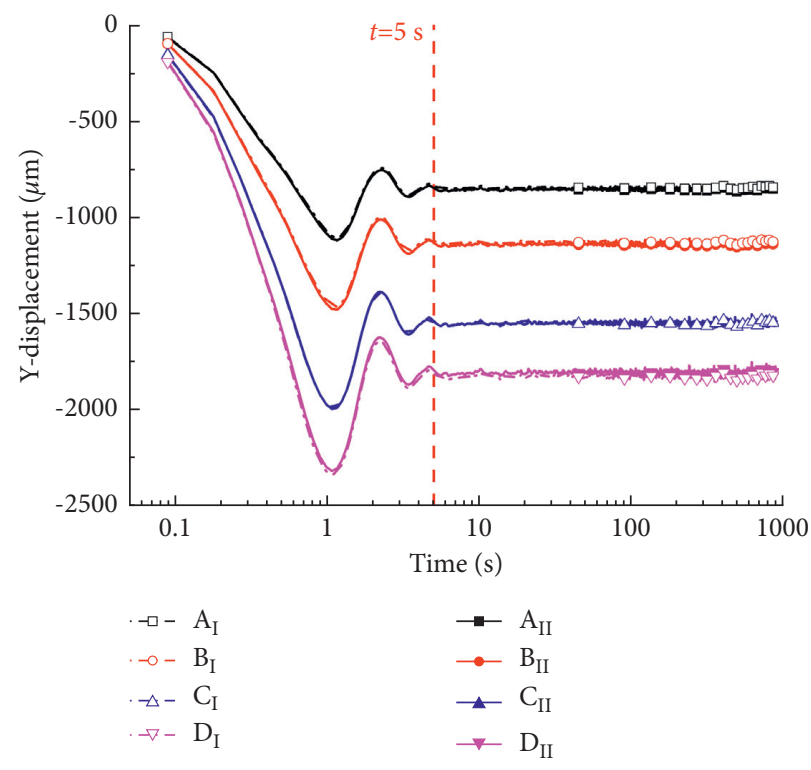

(b)

Figure 7: Time history curves of displacement. (a) X-displacement. (b) Y-displacement.

Figure 8 shows the time-average displacement distribution of the slope in the stable random vibration stage. The maximum displacement is located at the top on the left side. The maximum time-average displacement under the two scenarios is $1.22 \mathrm{~mm}$ and $1.01 \mathrm{~mm}$. In Scenario I, the zero displacement value near the plunge pool is located on the left side of the middle of the plunge pool floor, while the zero displacement value in Scenario II is located on the top of the left sidewall. The Y-displacement is negative, and the fluctuating pressures cause the slope compression deformation, which gradually decreases with the increase of the distance to the plunge pool. The maximum displacements are located at the floor midpoint of the plunge pool, and the maximum time-average displacements under the two scenarios are $-3.41 \mathrm{~mm}$ and $-3.35 \mathrm{~mm}$.

3.3.2. Distribution of Vibration Intensity. Vibration intensity is an important index to measure regional vibration strength. In this paper, the displacement standard deviation of the stable random vibration stage is used to study the distribution characteristics of slope vibration intensity under fluctuating pressures. Figure 9 displays the contour diagram of displacement standard deviation distribution under two scenarios. In Figure 9, the time-average displacement vibration intensity of the slope model is only at the micron level under the excitation of fluctuating pressures, indicating that the displacement vibration of the slope caused by fluctuating pressures is weak during high dam flood discharge.

When the fluctuating pressures at the bottom of the plunge pool were applied alone, the maximum vibration intensity of X-displacement is located at the top of the left side slope, and the vibration intensity is $5.30 \mu \mathrm{m}$. With increasing elevation, the vibration intensity of the left side slope increases gradually, which is roughly the same as the distribution of the time average of X-displacement of the slope in Figure 8(a). Affected by the fault zone of the left side 


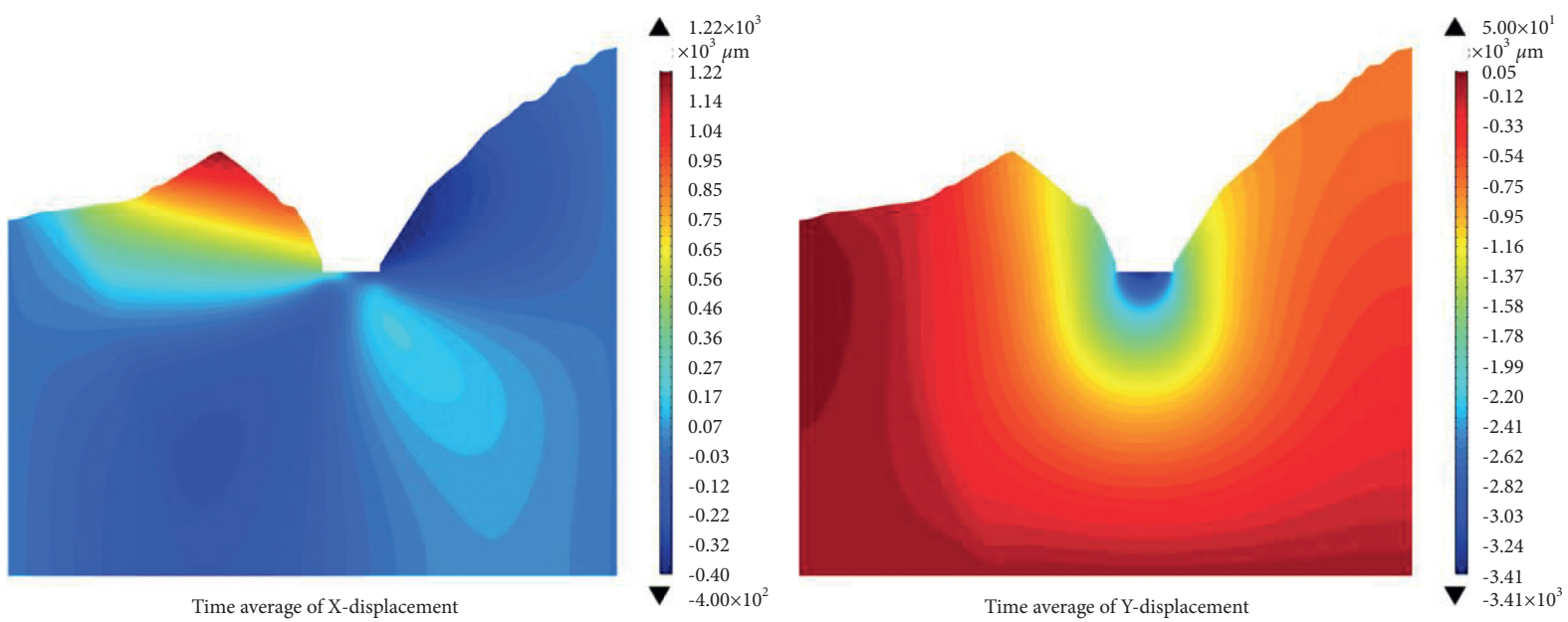

(a)

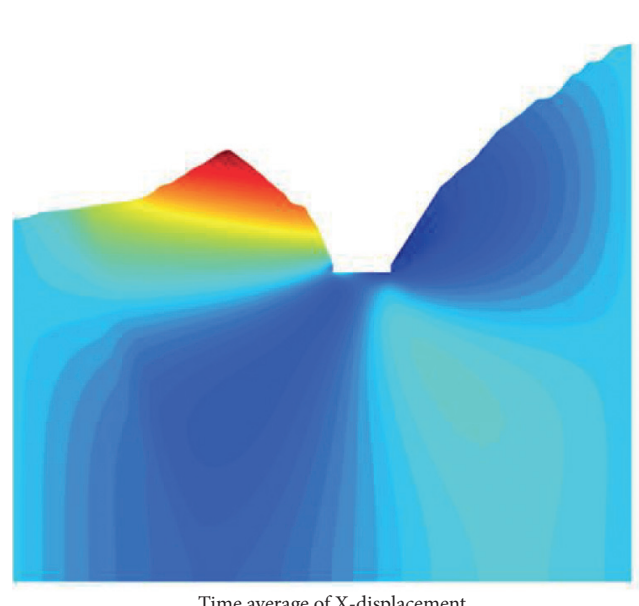

Time average of X-displacement
A $1.01 \times 10^{3}$

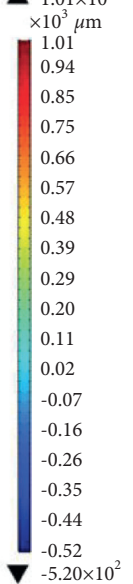

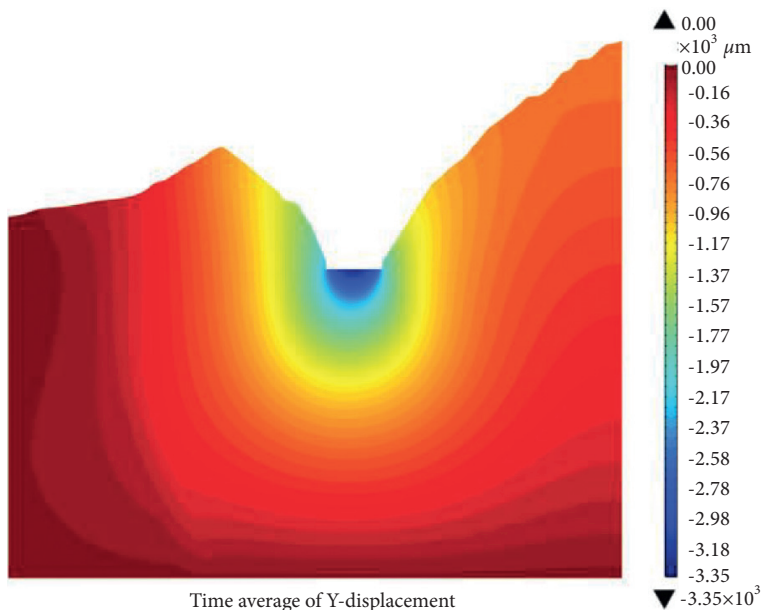

(b)

FIgURE 8: Time average of displacement.

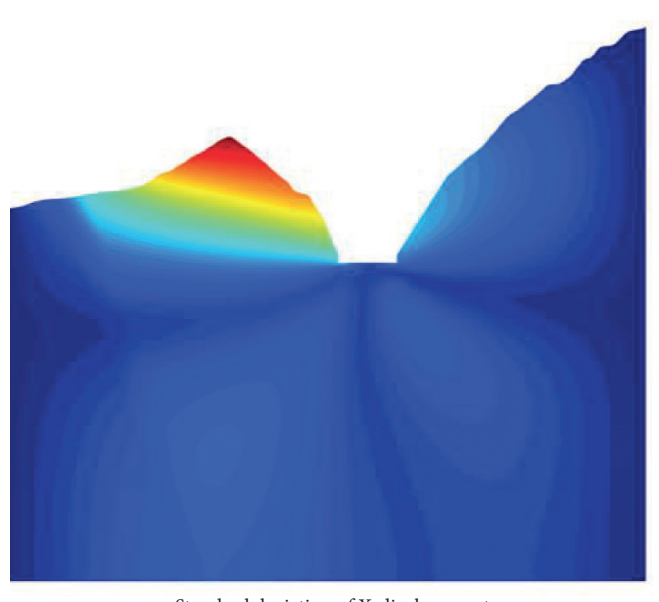

Standard deviation of X-displacement

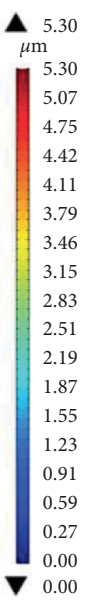

(a)

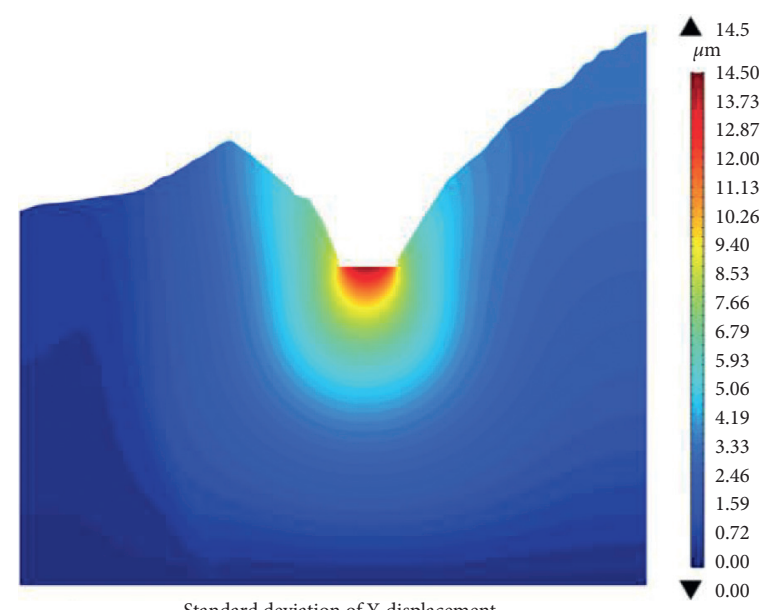

Standard deviation of Y-displacement

Figure 9: Continued. 


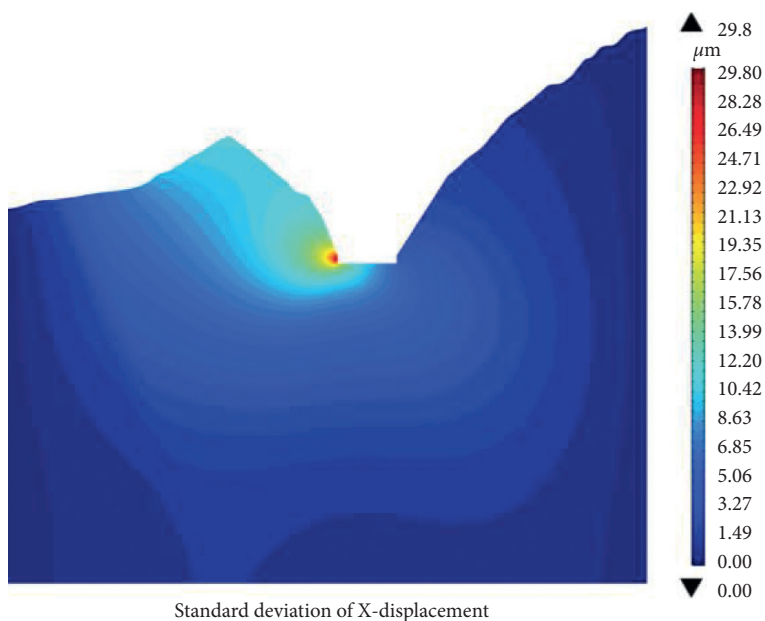

Standard deviation of X-displacement

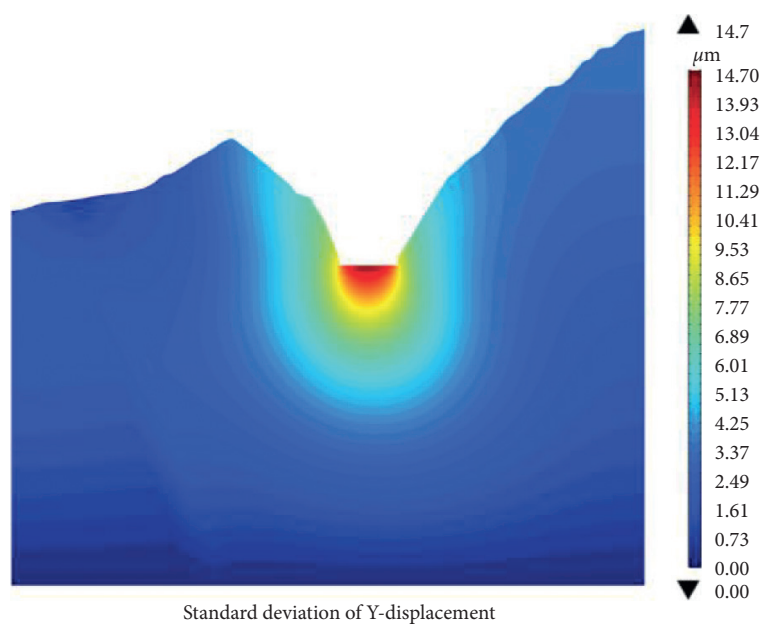

(b)

Figure 9: The standard deviation of displacement.

slope, the vibration intensities of the fault zone and its left rock layers are greatly reduced, indicating that fluctuating pressures have little effect on vibration within the range. It also reflects that the fault zone has a certain hindrance on the propagation of stress waves within this range. The vibration intensity of Y-displacement is mainly distributed in the plunge pool and the adjacent slope surface, and its peak vibration intensity is $14.50 \mu \mathrm{m}$. As the distance to the plunge pool increases, the vibration intensity gradually decreases, and the gradient change of the vibration intensity of the left side slope is greater than that of the right side slope.

When fluctuating pressures at the bottom and sidewall of the plunge pool were applied at the same time, the maximum vibration intensity of $\mathrm{X}$-displacement is transferred to the left sidewall of the plunge pool, and the peak vibration intensity is $29.80 \mu \mathrm{m}$. The vibration intensity at the top of the left side slope is $11.23 \mu \mathrm{m}$, which increases by $111.89 \%$ compared to that of Scenario I, indicating that the fluctuating pressures at the sidewall of the plunge pool have a great influence on the vibration intensity distribution of the left side slope. The vibration intensity distribution in the Y-displacement is the same as that of only under the fluctuating load at the bottom, and its peak vibration intensity is located at the point $\mathrm{O}$ of the plunge pool floor, and the vibration intensity is $14.7 \mu \mathrm{m}$.

In general, the vibration intensity of $\mathrm{X}$-displacement on the left side slope is greater than that of the right side slope under the excitation of the fluctuating pressures during high dam flood discharge. The higher the elevation is, the stronger the vibration will be. The vibration of the slope system in the $Y$ direction mainly occurs near the water plunge pool, and the vibration intensity gradually decreases with the increase of the distance to the plunge pool. The fluctuating pressures of the sidewall applied in Scenario II mainly affect the intensity distribution of displacement vibration in the $x$-direction of the slope.

3.3.3. Distribution and Attenuation of Kinetic Energy. Under the combined action of random fluctuating pressures and the PML absorbing boundary, the slope model is in a dynamic equilibrium state during the stable random vibration stage. To describe the kinetic energy distribution characteristics of the model under fluctuating pressures, the kinetic energy density is introduced to describe the kinetic energy of each particle in the slope model. It refers to the kinetic energy of the model per unit volume, which can be defined as

$$
W_{k}=\frac{1}{2} \rho v^{2},
$$

where $\rho$ is the density of the material, $\mathrm{kg} \mathrm{m}^{-3} ; v$ is the speed, $\mathrm{m} \mathrm{s}^{-2}$.

Here, the time-average kinetic energy density is used to describe the kinetic energy distribution of the slope model as shown in Figure 10. The kinetic energy of the slope model under the fluctuating pressures is only at the level of $10^{-6} \mathrm{~J}$, mainly distributed in the plunge pool and the adjacent slope surface. The maximum values of the kinetic energy density under two scenarios are located at point $\mathrm{O}$ on the bottom of the plunge pool, and the kinetic energy density values are $7.83 \mu \mathrm{J} / \mathrm{m}^{3}$ and $8.33 \mu \mathrm{J} / \mathrm{m}^{3}$, respectively. As the distance from the plunge pool increases, the kinetic energy density of the model decreases sharply, and the value of the kinetic energy density gradually tends to zero in the boundary area. The red lines in Figure 10 are the contours of the kinetic energy density of $0.5 \mu \mathrm{J} / \mathrm{m}^{3}$ and $1.0 \mu \mathrm{J} / \mathrm{m}^{3}$, respectively. Under the influence of fluctuating pressures on the sidewall of the plunge pool, the kinetic energy density in the sidewall area of the left side slope in Scenario II is greater than that in Scenario I, and the internal contour coverage area of the left side slope is significantly increased. In Scenario II, the kinetic energy density at the top of the left side slope is $1.60 \mu \mathrm{J} /$ $\mathrm{m}^{3}$, while that of Scenario II is $1.14 \mu \mathrm{J} / \mathrm{m}^{3}$, indicating that the fluctuating pressures on the sidewall increase the kinetic energy at the top of the left side slope to some extent.

The kinetic energy attenuation characteristics on the left side slope can be described by the time-average kinetic energy density ratio of each monitoring point on the line EF to point $\mathrm{O}$ in Figure 6. By fitting and analyzing the timeaverage kinetic energy density ratio of each monitoring 


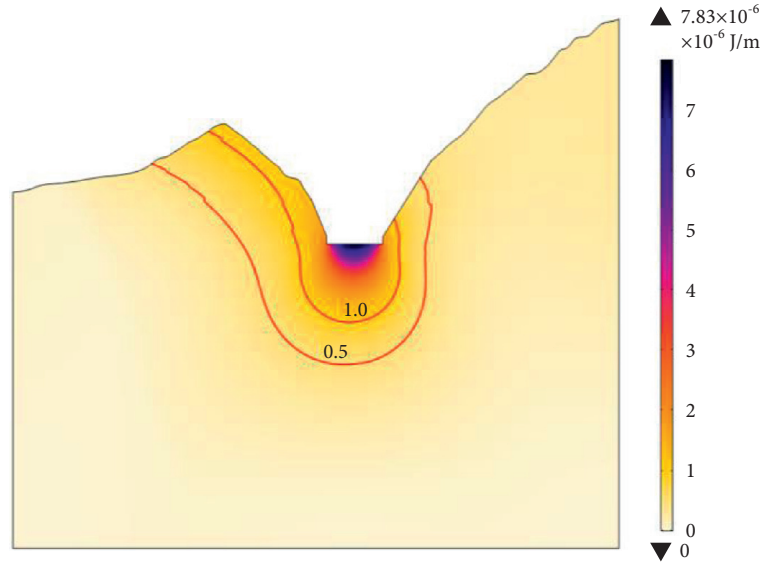

(a)

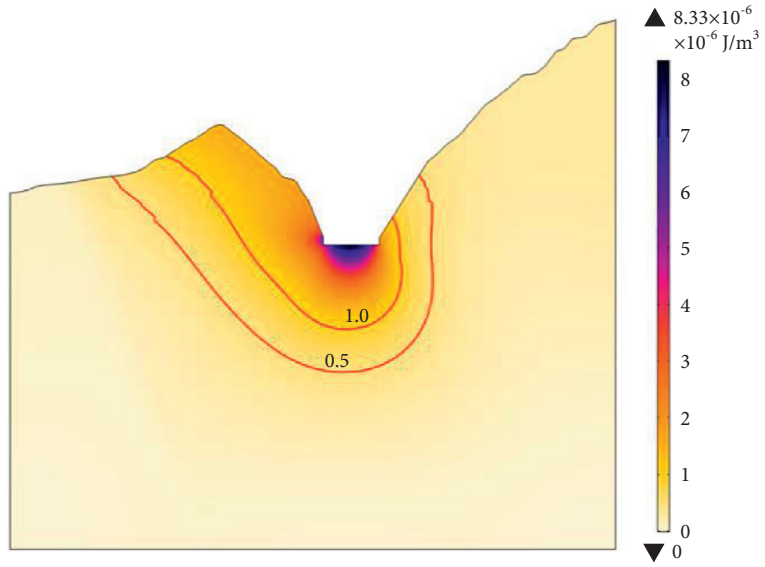

(b)

Figure 10: Distribution of the time-average kinetic energy density.

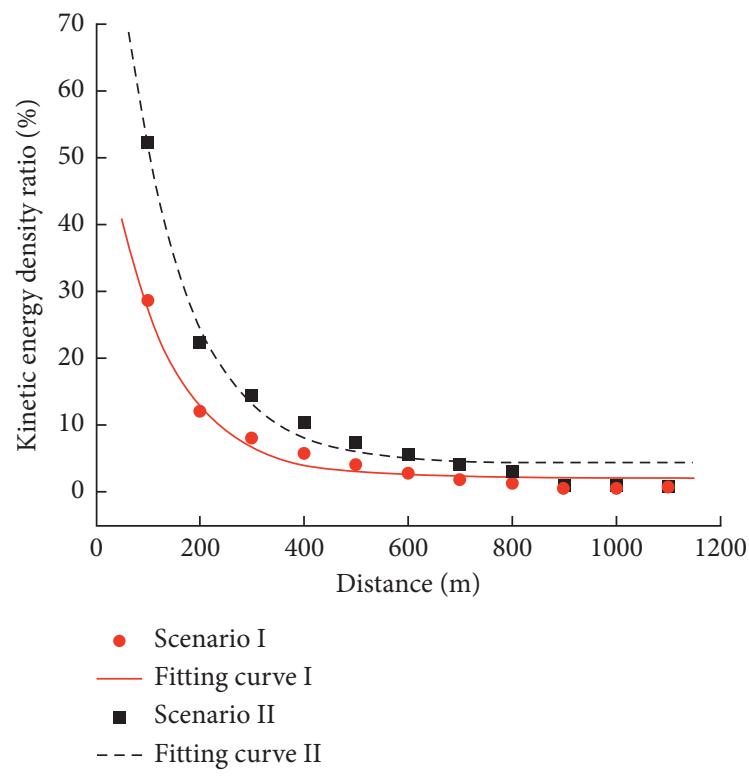

FIGURE 11: Kinetic energy attenuation curves.

point under the two scenarios, the kinetic energy attenuation curves as shown in Figure 11 were drawn. The kinetic energy density tends to decrease sharply and then stabilizes as the distance to point $\mathrm{O}$ increases. As the distance to point $\mathrm{O}$ increases, the kinetic energy density of the monitoring point decreases sharply and then tends to stabilize. According to the fitting curves, the time-average kinetic energy density ratio decays exponentially with the distance increases and satisfies

$$
y=a+b e^{-k x}
$$

where, $a, b, k$ are the fitting coefficients, and $R$ is the correlation coefficient. The fitting equation for Scenario $I$ is $y=2.2+59 e^{-0.0085 x}, a=2.2, b=59, k=0.0085, R^{2}=0.9877$. And the fitting equation for Scenario II is $y=4.4+110 e^{-0.0085 x}$, $a=4.4, b=110, k=0.0085, R^{2}=0.9913$.

The kinetic energy density ratio at each point in Scenario II is greater than that in Scenario I. The difference between the two scenarios gradually decreases with increasing distance from the point $\mathrm{O}$. Under the influence of the fault zone in the left side slope, the time-average ratios of $\mathrm{F}$ point and the two adjacent points are less than the fitted values, which may be caused by the energy loss of the stress wave after entering the fault zone from the dacite strata inside the slope.

In summary, the kinetic energy of the slope system is distributed mainly in the plunge pool and on the adjacent slope surface. The fluctuating pressures on the plunge pool bottom plate are the dominant factor affecting the kinetic energy distribution, and the water turbulence near the sidewall increases the kinetic energy of the left side slope to a certain extent. The kinetic energy on the left side slope in the horizontal direction decreases exponentially as the distance to the plunge pool increases, and the propagation energy of the stress wave also decreases because of the fault zone.

\section{Conclusions}

This paper focuses on the issue of slope vibration induced by high dam flood discharge. By analyzing the distribution of fluctuating pressures and the excitation-response characteristics of the slope during high dam flood discharge, the vibration response of the slope under fluctuating pressures was studied by a combination of hydraulic physical model test and numerical simulation. The following conclusions can be drawn:

(i) In the physical model test, the water turbulence in the plunge pool causes vibration of the water plunge pool structure during high dam flood discharge. The impact of discharge water makes the fluctuating pressures in the bottom plate larger than those of the sidewalls, and the fluctuation phenomenon in the bottom plate of the water plunge pool is dominated by the fluctuation of small-scale vortices. After the water flow dives into the surface water of the plunge pool, it produces severe swirling in front of the water tongue drop point, making the standard deviation of the fluctuating pressures at the sidewall 
of the plunge pool larger than that of the bottom plate, and the fluctuation phenomenon is more intense. The main fluctuation phenomenon at the sidewall is dominated by the fluctuation of largescale vortices, which have the characteristics of low frequencies and long fluctuation periods.

(ii) Triggered by fluctuating pressures, the left and right sides of the slope model deform towards the freeing surface region. The displacement and the vibration intensity of the left side slope in the horizontal direction are greater than those of the right side, and the intensity is only at the micron level. When the fluctuating pressures of the bottom plate and sidewall of the plunge pool are applied simultaneously, the peak vibration intensity in the horizontal direction is located at the left sidewall of the plunge pool, and the peak vibration intensity in the vertical direction is located at the midpoint of the floor.

(iii) The fluctuating pressures on the bottom plate are the dominant factor affecting the distribution of kinetic energy density, and the fluctuating pressures on the sidewall lead to the increase of kinetic energy density of the left side slope. The kinetic energy on the left side slope decreases exponentially with the increase of the distance to the water plunge pool, and the propagation energy of the stress wave at the fault zone decreases.

\section{Data Availability}

The experimental data used to support the findings of this study are included within the article.

\section{Conflicts of Interest}

The authors declare that they have no conflicts of interest.

\section{Acknowledgments}

This research was financially supported by the Guizhou Science and Technology Support Plan: Guizhou Science and Technology Joint Support (2019) no. 2890, and the Postdoctoral Science Foundation of China (Grant no. 2020M680975).

\section{References}

[1] M. C. He, Q. Wang, and Q. Y. Wu, "Innovation and future of mining rock mechanics," Journal of Rock Mechanics and Geotechnical Engineering, vol. 13, pp. 234-243, 2021.

[2] Q. Wang, M. He, S. Li, and Z. Jiang, "Comparative study of model tests on automatically formed roadway and gob-side entry driving in deep coal mines," International Journal of Mining Science and Technology, vol. 31, pp. 591-601, 2021.

[3] M. Z. Gao, J. Xie, Y. N. Gao, and W. Wang, "Mechanical behavior of coal under different mining rates: a case study from laboratory experiments to field testing," International Journal of Mining Science and Technology, vol. 31, no. 5, pp. 825-841, 2021.

[4] M. Z. Gao, J. Xie, J. Guo, and Y. Lu, "Fractal evolution and connectivity characteristics of mining-induced crack networks in coal masses at different depths," Geomechanics and Geophysics for Geo-Energy and Geo-Resources, vol. 7, no. 1, 2021.

[5] X. S. Li, K. Peng, J. Peng, and D. Hou, "Experimental investigation of cyclic wetting-drying effect on mechanical behavior of a medium-grained sandstone," Engineering Geology, vol. 293, Article ID 106335, 2021.

[6] X. S. Li, K. Peng, J. Peng, and H. Xu, "Effect of cyclic wettingdrying treatment on strength and failure behavior of two quartz-rich sandstones under direct shear," Rock Mechanics and Rock Engineering, vol. 54, pp. 5953-5960, 2021.

[7] Y. Wang, B. Zhang, B. Li, and C. H. Li, "A strain-based fatigue damage model for naturally fractured marble subjected to freeze-thaw and uniaxial cyclic loads," International Journal of Damage Mechanics, vol. 30, no. 6, pp. 1594-1616, 2021.

[8] G. Fan, J. J. Zhang, and J. B. Wu, "Dynamic response and dynamic failure mode of a weak intercalated rock slope using a shaking table," Rock Mechanics and Rock Engineering, vol. 49, no. 8, pp. 3423-3256, 2016.

[9] C. Zhu, M. C. He, M. Karakus, X. Zhang, and Z. Tao, "Numerical simulations of the failure process of anaclinal slope physical model and control mechanism of negative Poisson's ratio cable," Bulletin of Engineering Geology and the Environment, vol. 80, pp. 3365-3380, 2021.

[10] C. Zhu, M. C. He, M. Karakus, X. B. Cui, and Z. G. Tao, "Investigating toppling failure mechanism of anti-dip layered slope due to excavation by physical modelling," Rock $\mathrm{Me}$ chanics and Rock Engineering, vol. 53, no. 11, pp. 5029-5050, 2020.

[11] Z. G. Tao, C. Zhu, M. C. He, and M. Karakus, "A physical modeling-based study on the control mechanisms of Negative Poisson's ratio anchor cable on the stratified toppling deformation of anti-inclined slopes," International Journal of Rock Mechanics and Mining Sciences, vol. 138, Article ID 104632, 2021.

[12] W. F. Chen and T. Sawada, "Earthquake-induced slope failure in nonhomogeneous, anisotropic soils," Soils and Foundations, vol. 23, no. 2, pp. 125-139, 1983.

[13] Y. G. Hu, W. B. Lu, M. Chen, and P. Yan, "Comparison of blast-induced damage between presplit and smooth blasting of high rock slope," Rock Mechanics and Rock Engineering, vol. 47, no. 4, pp. 1307-1320, 2014.

[14] E. M. Shumakova, A. V. Kotlyakov, and G. V. Shumakov, "The effect of vibrations in the Zhigulevskii hydropower structure on soils in the nearby territories of Tolyatti city," Water Resources, vol. 37, no. 3, pp. 306-310, 2010.

[15] A. V. Kotlyakov, E. M. Shumakova, and S. A. Artemev, "Dynamics of the coastal zone of the Kuibyshev and Saratov reservoirs in the Tolyatti area and its correlation with the operation regime of the Zhigulevskaya HPP," Water Resources, vol. 34, no. 12, pp. 657-662, 2007.

[16] C. Liang, "Research on vibration mechanism and reduction methods for structures and surrounding ground under excitations generated by high dam flood discharge," Doctoral Dissertation, Tianjin University, Tianjin, China, 2017.

[17] S. J. Li, J. J. Lian, and Q. P. Ouyang, "Study on source of high dam discharge-induced vibration in dam region and site," Water Resources and Hydropower Engineering, vol. 45, no. 9, pp. 47-51, 2014, in Chinese.

[18] C. Liang, J. L. Zhang, J. J. Lian, and F. Liu, "Probabilistic analysis for the response of nonlinear base isolation system under the ground excitation induced by high dam flood discharge," Earthquake Engineering and Engineering Vibration, vol. 16, no. 4, pp. 841-857, 2017. 
[19] D. S. Leng, M. Yang, and B. Ma, “The vibration characteristics of slabs in plunge pool based on archetypal observation of Jinping - I Dam," South-to-north water Transfers and water Science \& Technology, vol. 14, no. 6, pp. 105-110, 2016, in Chinese.

[20] C. C. Zhang and J. Sun, "Numerical simulation on the typical flow pattern sin the plunge pool of high dam," Journal of Xi'an University of Technology, vol. 22, no. 1, pp. 24-28, 2006, in Chinese.

[21] B. Ma, S. Liang, L. Chao, and Y. Li, "Experimental research on an improved slope protection structure in the plunge pool of a high dam," Water, vol. 9, no. 9, p. 671, 2017.

[22] T. S. Dong, "Research on energy dissipation mechanism and fluctuating pressure of special - shaped stilling basin," Doctoral Dissertation, Tianjin University, Tianjin, China, 2015.

[23] Y. Zhang, "Investigations on source characteristics and propagation laws of the ground vibration induced by high dam flood discharge," Doctoral Dissertation, Tianjin University, Tianjin, China, 2015.

[24] S. J. Li, "Research on vibration source of Xiangjiaba dam flowinduced sites vibration," Master's Dissertation, Tianjin University, Tianjin, China, 2013.

[25] Z. Yao, "Research on the flow-induced vibration response characteristics of slabs in plunge pool of jinping-I high arch dam," Master's Dissertation, Tianjin University, Tianjin, China, 2013.

[26] S. W. Qi, F. Q. Wu, F. Z. Yan, and C. Liu, Rock Slope Dynamic Response Analysis, Science Press, Beijing, China, 2007.

[27] J. Lysmer and R. L. Kuhlemeyer, "Finite dynamic model for infinite media," Journal of the Engineering Mechanics Division, vol. 95, no. 4, pp. 859-878, 1969.

[28] C. J. Fan, H. O. Wen, S. Li, G. Bai, and L. J. Zhou, "Coal seam gas extraction by integrated drillings and punchings from floor roadway considering hydraulic-mechanical coupling effect," Geofluids, Article ID 5198227, 2022.

[29] C. J. Fan, L. Yang, G. Wang, Q. M. Huang, X. Fu, and H. O. Wen, "Investigation on coal skeleton deformation in $\mathrm{CO} 2$ injection enhanced $\mathrm{CH} 4$ drainage from underground coal seam," Frontiers of Earth Science, vol. 9, Article ID 766011, 2021.

[30] C. J. Fan, S. Li, M. K. Luo, W. Z. Du, and Z. H. Yang, "Coal and gas outburst dynamic system," International Journal of Mining Science and Technology, vol. 27, no. 1, pp. 49-55, 2017.

[31] C. J Fan, S. Li, D. Elsworth, J. Han, and Z. H. Yang, "Experimental investigation on dynamic strength and energy dissipation characteristics of gas outburst prone coal," Energy Science \& Engineering, vol. 8, no. 4, pp. 1015-1028, 2020.

[32] J. P. Bérenger, "A perfectly matched layer for the absorption of electromagnetic waves," Journal of Computational Physics, vol. 114, no. 2, pp. 185-200, 1994.

[33] B. Kaltenbacher, M. Kaltenbacher, and I. Sim, "A modified and stable version of a perfectly matched layer technique for the 3-d second order wave equation in time domain with an application to aeroacoustics," Journal of Computational Physics, vol. 235, no. 100, pp. 407-422, 2013.

[34] Z. N. Xie, R. Matzen, P. Cristini, and D. Komatitsch, "A perfectly matched layer for fluid-solid problems: application to ocean-acoustics simulations with solid ocean bottoms," Journal of the Acoustical Society of America, vol. 140, no. 1, pp. 165-175, 2016.

[35] W. C. Chew, J. M. Jin, and E. Michielssen, "Complex coordinate stretching as a generalized absorbing boundary condition," Microwave and Optical Technology Letters, vol. 15, no. 6, pp. 363-369, 1997.

[36] J. M. Jin, Theory and Computation of Electromagnetic Fields, pp. 386-390, John Wiley \& Sons, Inc., Hoboken, NJ, USA, 2010.

[37] W. B. Jian, Z. Hu, X. Fan, and R. Hong, "Research on responses of slope under cyclic load," Chinese Journal of Rock Mechanics and Engineering, vol. 27, no. 12, pp. 2562-2567, 2008, in Chinese.

[38] X. M. Peng, H. Z. Guo, and R. Zhang, "Wavelet analysis on flow fluctuating pressure acting on plunge pool slope," Journal of Hydraulic Engineering, vol. 34, no. 8, pp. 26-31, 2003, in Chinese.

[39] H. Z. Guo, "Study on criteria for judging the safety of apron slabs in plunge pool," Master's Dissertation, Tianjin University, Tianjin, China, 2004. 